\title{
Configurações
}

Revista Ciências Sociais

\section{Olhar sociológico sobre o mundo: debates nas escolas secundárias. Reflexões e práticas no Norte e Centro do País}

A sociological perspective of the world: debates in high schools. Reflections and practices in the North and Centre of Portugal

Regard sociologique sur le monde: débats dans les lycées. Réflexions et pratiques dans le Nord et dans le Centre du Portugal

ÂNGELA ALVES, BEATRIZ LACERDA, CÁTIA COSTA, CRISTINA PARENTE e NATÁLIA AZEVEDO

\section{OpenEdition}

\section{Journals}

\section{Edição electrónica}

URL: https://journals.openedition.org/configuracoes/13842

DOI: 10.4000/configuracoes.13842

ISSN: 2182-7419

\section{Editora}

Centro de Investigação em Ciências Sociais

Edição impressa

Paginação: 43-64

ISSN: 1646-5075

\section{Refêrencia eletrónica}

ÂNGELA ALVES, BEATRIZ LACERDA, CÁTIA COSTA, CRISTINA PARENTE e NATÁLIA AZEVEDO, «Olhar sociológico sobre o mundo: debates nas escolas secundárias. Reflexões e práticas no Norte e Centro do País», Configurações [Online], 28 | 2021, posto online no dia 15 dezembro 2021, consultado o 28 dezembro 2021. URL: http://journals.openedition.org/configuracoes/13842 ; DOI: https://doi.org/ 10.4000 /configuracoes. 13842 
ALVES, Ângela; LACERDA, Beatriz; COSTA, Cátia; PARENTE, Cristina; AZEVEDO, Natália - Olhar sociológico sobre o mundo: debates nas escolas secundárias. Reflexões e práticas no Norte e Centro do País. Configurações [em linha]. 28 (2021) p. 43-64.

\title{
Olhar sociológico sobre o mundo: debates nas escolas secundárias. Reflexões e práticas no Norte e Centro do País
}

\author{
ÂNGELA ALVES* \\ Estudante de Mestrado em Sociologia da Faculdade de Letras da Universidade do Porto \\ BEATRIZ LACERDA** \\ Estudante de Mestrado em Sociologia da Faculdade de Letras da Universidade do Porto \\ CÁTIA COSTA*** \\ Estudante de Mestrado em Sociologia da Faculdade de Letras da Universidade do Porto \\ CRISTINA PARENTE**** \\ Departamento de Sociologia da Faculdade de Letras da Universidade do Porto e Instituto de Sociologia da \\ Universidade do Porto \\ NATÁLIA AZEVEDO***** \\ Departamento de Sociologia da Faculdade de Letras da Universidade do Porto e Instituto de Sociologia da \\ Universidade do Porto
}

\begin{abstract}
Resumo
O artigo propõe uma narrativa experiencial do projeto "Olhar sociológico sobre o mundo: debates nas escolas secundárias", integrando uma análise reflexiva sobre a sua construção, implementação e avaliação. Os princípios teóricos que o inspiram radicam numa proposta combinatória entre educação formal e não formal e na aprendizagem significativa para os públicos do ensino secundário. O projeto integra-se na terceira missão da Universidade e afirma-se como uma iniciativa de educação de pares (públicos-alvo, equipa mentora de estudantes e professores universitários). Pelos resultados, a avaliação da iniciativa autoriza um exercício de replicação: um possível guia de aprendizagem para outros atores e atividades que se pretendam desenvolver.
\end{abstract}

Palavras-chave: Sociologia, ensino secundário, aprendizagem pela prática, educação de pares.

*E-mail: angelaalves2000@hotmail.com |

**E-mail: bunny.lacerda @gmail.com |

***E-mail: catia_costa98@live.com.pt |

****E-mail: cparente@letras.up.pt | ORCID ID: https://orcid.org/0000-0002-7500-7050

*****E-mail: nazevedo@letras.up.pt | ORCID ID: https://orcid.org/0000-0002-6387-7868 


\begin{abstract}
A sociological perspective of the world: debates in high schools. Reflections and practices in the North and Centre of Portugal
\end{abstract}

The article proposes an experiential narrative of the project "A sociological perspective of the world: debates in high schools", integrating a reflexive analysis on its construction, implementation and evaluation. The theoretical principles are rooted in a combinatorial proposal between formal and non-formal education and on meaningful learning for high school audiences. The project is part of the university's third mission and is affirmed as a peer education initiative (target audiences, mentoring team of students and university professors). According to the results, the evaluation of the initiative authorises a replication exercise: a possible learning guide for other actors and activities that are intended to be developed.

Keywords: Sociology, secondary education, learning by practice, peer education.

\title{
Resumé
}

Regard sociologique sur le monde : débats dans les lycées. Réflexions et pratiques dans le Nord et dans le Centre du Portugal

L'article propose un récit expérientiel du projet « Regard sociologique sur le monde : débats dans les lycées », avec une analyse réflexive sur sa construction, sa mise en œuvre et son évaluation. Les principes théoriques qui l'inspirent sont enracinés dans une proposition combinatoire entre l'éducation formelle et non formelle et sur l'apprentissage significatif pour les lycéens. Le projet fait partie de la troisième mission de l'Université et s'affirme comme une initiative d'éducation par les pairs (lycéens, équipe de mentorat d'étudiants et professeurs d'université). Selon les résultats, l'évaluation de l'initiative autorise un exercice de réplication : un guide d'apprentissage possible pour d'autres acteurs et activités que l'on souhaite développer.

Mots-clés: Sociologie, enseignement secondaire, apprentissage par la pratique, éducation par les pairs.

\section{Preâmbulos: dos antecedentes do projeto aos pressupostos de base das experiências em contexto escolar}

Em 2017, a Associação Portuguesa de Sociologia (APS) organizou uma iniciativa que teve como objetivo promover a disciplina da Sociologia nas escolas secundárias do país, através de sessões dinâmicas e interativas entre pares. A iniciativa, intitulada "Olhar sociológico sobre o mundo: debates nas escolas secundárias", integrou como atores intermediários equipas de estudantes universitários dos ciclos de estudos em Sociologia que, acompanhados de professores dos departamentos de Sociologia das universidades portuguesas, foram entendidos pela APS como os interlocutores que melhor fariam a ponte entre 
os dois níveis de ensino: o ensino secundário e o ensino superior. A proximidade etária entre os dois grupos de estudantes, a partilha de modelos de comunicação e a vivência de expectativas semelhantes face ao futuro configuraram-se como elementos decisivos não só para conceber o projeto de "ida da Sociologia às escolas secundárias", mas também para dinamizar e covivenciar entre pares juvenis (Svenson, 1988; Freire, 1996) as possíveis abordagens ao social e à Sociologia. Esta proposta veio também responder a uma das mais longas missões da APS, que é a de aproximar a Sociologia dos alunos do ensino secundário, que tem sido terreno infértil para a consolidação desta disciplina, não só pela sua natureza facultativa mas também pela ausência de docentes especializados na área (Martins e Fraga, 2021) ${ }^{1}$.

À data da iniciativa, a recetividade de estudantes e da direção dos cursos de primeiro e segundo ciclos do Departamento de Sociologia (DS) da Faculdade de Letras da Universidade do Porto (FLUP) foi imediata e desafiadora: criou-se em 2017 uma equipa de trabalho que concebeu uma proposta de abordagem ao universo pedagógico-didático, científico e profissional da Sociologia, proposta aceite pela APS e que, desde então, tem sido o mote de um conjunto de experiências em contexto escolar dinamizadas pelo norte e centro do país. As sessões que realizámos decorreram, entre 2017 até à data do presente texto, em 11 escolas secundárias, envolvendo um total de 762 participantes, entre estudantes e professores do ensino secundárioº ${ }^{2}$.

Estes projetos têm relevância científico-pedagógica quando atentamos às diferentes escalas de enquadramento da relação entre universidade e população juvenil e estudantil. Os discursos e as práticas científico-pedagógicas, transversais do ponto de vista institucional e em relação estreita com a comunidade envolvente, em particular os potenciais estudantes pré-universitários, reenviam-nos para estratégias de aproximação e envolvimento das comunidades educativas e pedagógicas. Tais estratégias reportam, por um lado, a espaços-tempos mais microssituados, nos quais se partilha a perspetiva sociológica na análise de temáticas sociais e as virtualidades possíveis do exercício de uma

1 A institucionalização da Sociologia no ensino secundário e superior português data do final da década de 1970, reforçando por isso a urgência da necessidade de "fornecer formação e informação fundamental para os cursos superiores de Sociologia, Antropologia e Ciências Sociais, [...] nos ramos científico e de formação de docentes.” (Portugal in Neuhold, 2013, p. 140). Apesar da sua afirmação nas universidades e mesmo com a fundação da APS em 1985, que ajudou a consolidar a “(...) sociologia profissional [que] ganhou rapidamente dimensão e importância pela capacidade de contribuir para a resolução informada de problemas múltiplos" (Almeida, 2005) -, os sociólogos sempre tiveram dificuldades em afirmar-se na lecionação no ensino secundário. Desde 1979, momento em que a formação em Sociologia integrou o grupo de formações elegíveis para lecionar a disciplina, os sociólogos quase nunca pertenceram aos primeiros escalões (que têm prioridade no ensino secundário) (Neuhold, 2013). À exceção de um ano, no início dos anos 1980, o curso de Sociologia foi sempre ultrapassado por outras áreas, como Direito, Economia e Filosofia, por exemplo, no acesso direto à docência da disciplina, desafio ainda hoje debatido pela APS, o que não só fragiliza a identidade profissional destes sociólogos, como enfraquece o posicionamento da disciplina (opcional) na oferta curricular (Martins e Fraga, 2021).

$2 \mathrm{O}$ anexo 1 integra informação sobre as escolas secundárias que aderiram ao projeto. 
atividade profissional nesta área - por exemplo, relembre-se o Dia Aberto da Sociologia do DS/FLUP, que, desde 2007, com maior ou menor periodicidade, constitui uma atividade de diálogo entre a formação graduada em Sociologia e as escolas secundárias, com particular incidência daquelas em que a disciplina de Sociologia tende a estar presente nos currículos escolares; e, por outro lado, de forma cada vez mais assumida, à terceira missão da universidade, com as múltiplas estratégias de aproximação às escolas e aos estudantes pré-universitários que a Universidade do Porto (UP) tem concebido: por exemplo, projetos como a U.Porto nas escolas, a Mostra da U.Porto e a Universidade Júnior ${ }^{3}$, que permitem aos estudantes dos ensinos básico e secundário vivenciar in loco experiências de ensino e de investigação, e de satisfazer as necessidades de informação sobre as escolhas pessoais e profissionais de futuro.

Numa escala macro de enquadramento, este mesmo projeto remete-nos para as diretrizes estratégicas e conciliatórias das políticas educativas europeias e nacionais se nos reportarmos, entre outros, ao Quadro Estratégico da União Europeia Educação e Formação 2020, e aos pressupostos-base de uma aprendizagem ao longo da vida e de uma aprendizagem que tenha lugar em todos os contextos (formal, não formal e informal) ${ }^{4}$. Entre outras dimensões teóricas e operacionais, pressupõem-se como alicerces-base da educação de um jovem a relação entre a formação (escolar e/ou profissional) e o potencial mercado de trabalho, as competências transversais e transferíveis, adquiridas em contextos formais, não formais e informais de educação e a valorização de uma cultura de cidadania ativa e reflexiva que, entre muitos outros aspetos, passa por uma relação estreita entre os jovens e os contextos envolventes de aprendizagens. Acresce o facto dos contextos formais de educação - no caso, a educação escolar pré-universitária e universitária - se cruzarem, de modo estratégico e necessário, com as aprendizagens paralelas à educação formal que, no projeto em causa, se situam também elas nos espaços-tempos da escola.

Os processos de educação concebem-se de modo integrado e sob a alçada de uma visão transversal das dimensões formais e não formais e informais da educação. A atividade aqui em causa operacionaliza, no campo dos seus possíveis enquanto projeto e experiência, a partilha de conteúdos e de instrumentos em contex to escolar que reforçam as aprendizagens formais dos currículos (no caso, da Sociologia no ensino secundário), através de uma abordagem de educação não formal, liderada por pares. Não se trata de replicar, informalmente,

3 Ver U.Porto na Comunidade (https://sigarra.up.pt/up/pt/web_base.gera_pagina?p_pagina=uporto-na-comunidade), onde se destacam a Universidade Júnior (https://universidadejunior.up.pt/), a Mostra da U.Porto (http://www.mostra.up.pt/) e a U.Porto nas escolas (https://sigarra.up.pt/up/pt/web_base. gera_pagina?p_pagina=uporto-nas-escolas). Consultados, pela última vez, a 9/04/2021.

4 Ver Plataforma da Comissão Europeia no domínio da Educação e Formação: https://ec.europa.eu/ education/education-in-the-eu/about-education-and-training-in-the-eu_pt, consultada, pela última vez, a $9 / 04 / 2021$. 
modos e temas das ciências sociais curriculares, em formato de teoria condensada, mas antes de “(...) transmitir hábitos intelectuais fundamentalmente ligados a estas disciplinas. Do mesmo modo que os alunos adquirem o hábito de fazer quotidianamente o levantamento de temperatura para objetivar e tomar assim consciência dos fenômenos meteorológicos, eles poderiam ser treinados para a observação e para a objetivação do mundo social" (Lahire, 2014, p. 55). Abre também novas perspetivas sobre a futura relação com a formação superior e a entrada no mercado de trabalho por via de experiências potenciadas por jovens pares numa relação de proximidade em sala de aula.

Num contexto contemporâneo em que o modelo de aprendizagem ao longo da vida atravessa grupos etários, sociais e profissionais, e se configura na transversalidade dos formatos e espaços-tempos educativos, as virtualidades do projeto que desenvolvemos situam-se na articulação possível entre os conhecimentos e as competências exigidas pelos currículos escolares - na relação mais imediata com as temáticas sociais - e as propostas de abordagem colaborativa, lúdica, prática - por via de uma mensagem dirigida aos jovens estudantes do ensino secundário. Sem integrar como objetivo a discussão e a valoração dos limites e das virtualidades decorrentes de um posicionamento vertical e rígido sobre dicotomias educativas (educação formal vs. educação não formal, por exemplo), o projeto desenvolvido procura dimensionar, com uma prática sociológica, reflexiva e pragmática, uma resposta a um desafio educativo formal: salientar o olhar sociológico na análise de temas sociais estruturantes e os possíveis perfis profissionais de futuros licenciados em Sociologia, a partir da “(...) capacitação dos jovens estudantes para uma participação consciente na vida social e política" (Jinkings, 2007, p. 116). Paralelamente, constitui uma oportunidade de aprendizes de sociólogos, dos $2 .^{\circ}$ e $3 .^{\circ}$ anos da licenciatura e do $1 .^{\circ}$ ano do mestrado, refletirem sobre a sua experiência educativa e a partir dela construírem conteúdos e materiais pedagógicos, bem como formas de os transmitir aos seus pares num exercício explicativo e informativo de educação de pares (Svenson, 1988; Freire, 1996; Ausubel, 1982), contribuindo também para formação da sua identidade pessoal e profissional. Por último, coube às docentes da equipa de trabalho um papel de monitorização do processo com a assunção da autonomia dos estudantes na conceção e dinamização do projeto; a partilha de métodos de trabalho; a discussão e covalidação das atividades propostas; a avaliação ongoing do projeto; a mediação institucional com a APS, que financiou os custos inerentes ao projeto (viagens, refeições e materiais para as atividades); a partilha de estímulos e orientações teóricas e operacionais. Como pressuposto, vivenciou-se uma paridade relativa tanto entre estudantes (nos dois níveis de ensino) como entre estudantes e docentes da mesma equipa de trabalho. 


\section{Dos discursos às práticas: traços de um desenho de projeto ongoing}

Operacionalizar o desafio lançado pela APS colocou-nos perante a discussão sobre os elementos necessários ao desenho das sessões temáticas, desde a formulação dos objetivos, seleção e configuração dos temas, até à escolha dos métodos pedagógicos para a dinamização das apresentações e discussões grupais, passando pelos instrumentos de avaliação e reconstrução das sessões, numa estratégia de ação e retroação capaz de introduzir melhorias finda e feita a reflexão sobre cada sessão. Narramos nos próximos pontos a experiência vivida.

\subsection{A equipa líder do projeto: quem somos e como nos organizámos?}

Após a candidatura ao concurso aberto a todas as universidades do país, foi atribuída a realização do projeto na zona Norte à equipa da FLUP, que contava à época com 6 membros, 4 estudantes e 2 professoras. Ao longo do tempo, o número de alunos que integrou a equipa foi aumentando, sendo rara a repetição da mesma equipa de estudantes em cada escola. Em 2021, passados 4 anos do arranque das sessões, e após alterações na equipa, sobretudo pela interrupção dos estudos em Sociologia, a equipa conta com 20 membros, pertencentes à Licenciatura e ao Mestrado em Sociologia da mesma Faculdade.

Para agendar o nosso trabalho com as escolas, duas vias foram seguidas. A primeira, e a mais comum, foi através do contacto com a APS. As escolas respondem à chamada da APS, que as distribui, segundo a sua localização geográfica de proximidade, às diferentes equipas das universidades nacionais. De notar, algumas exceções como a apresentação de sessões em duas escolas da zona Centro (ver anexo 1), ora porque a universidade correspondente à zona não pôde, no momento, responder ao convite da instituição, ora porque as escolas pedem especificamente uma universidade para desenvolver a ação. A outra alternativa tem sido os membros da equipa comunicarem com as escolas secundárias que frequentaram e procederem ao agendamento via e-mail.

As sessões foram apresentadas por 4 membros da equipa (e por 3, em contex to da pandemia), alterando-se este número sempre que solicitado pelas escolas. A seleção dos membros para cada visita foi feita em reuniões de equipa, reuniões preparatórias para a ordem de trabalhos para as escolas correspondentes. Os critérios de escolha dos elementos de ida às escolas basearam-se, sobretudo, na disponibilidade dos membros e no número de idas às escolas, sendo priorizados, em cada momento, aqueles que tinham participado em menos visitas às instituições de ensino secundário, desde que acompanhados por um/a colega com experiência, num sistema de aprendizagem rotativa.

Todas as sessões contaram com uma dinâmica de quebra-gelo, a que se seguiu um momento inicial mais expositivo sobre a Sociologia e/ou as Ciências 
Sociais, e que serviu também de diagnóstico para determinar a forma como orientar o segundo e mais longo momento de dinâmicas didáticas, como jogos e debates. Os últimos momentos das sessões ficaram sempre reservados para o preenchimento dos inquéritos, e para uma conversa de encerramento, onde se esclareceram dúvidas, se partilharam contactos e, muitas vezes, a pedido das turmas, histórias pessoais dos elementos da equipa sobre os seus percursos universitários.

\subsection{Planeamento das sessõe: pressupostos pedagógico-didáticos de partida}

Segundo os parâmetros de uma metodologia de projeto, o planeamento da totalidade das sessões contemplou critérios focalizados nos objetivos, nas atividades, nos métodos de abordagem e nos resultados esperados, em estreita relação com as sugestões emanadas dos professores do ensino secundário, previamente contactados e convidados a aderirem à atividade. Procurou-se sempre responder às necessidades e expectativas dos professores, trocando com eles informações, anteriores à preparação da sessão e de modo a atender às particularidades da escola, da turma e dos estudantes, não deixando de responder aos objetivos a que nos comprometemos com a APS.

Do ponto de vista substantivo, os conteúdos foram escolhidos a partir da indicação dos temas tratados nas aulas pelos professores do ensino secundário ou de acordo com aquilo que a nossa equipa considerava, à data, os temas mais presentes e centrais entre os jovens. A este propósito, escolhemos temáticas centrais nos mass media, nas redes sociais, na escola e nos espaços de interação dos jovens. Temáticas associadas às desigualdades sociais, e em particular as desigualdades de género e na educação, foram consideradas as mais pertinentes e com recetividade muito positiva entre os jovens estudantes; por outro lado, e a propósito da relação mais estreita entre as realidades quotidianas dos jovens estudantes do ensino secundário e as vivências universitárias da Sociologia da equipa de trabalho, procurou-se tratar temáticas ligadas aos currículos universitários.

\subsection{A contínua reconstrução das sessões: o portefólio de chegada}

A equipa de projeto desenvolveu um trabalho interno de preparação, conceção e discussão prévias dos formatos das sessões, assente na partilha, na simulação e no treino antecipado das competências de interação entre os diferentes elementos da equipa, bem como na coconstrução dos materiais e dos suportes textuais e visuais para cada sessão.

A maior preocupação com a estrutura das sessões, independentemente das suas adaptações, foi sempre a de encontrar um equilíbrio entre os momentos 
mais expositivos e os mais interativos. Se, por um lado, se espera uma transmissão de conceitos-chave da disciplina, por outro lado, pode considerar-se que, na educação por pares, estes conceitos serão mais consolidados quando através de dinâmicas informais e participadas.

Por ocasião da realização da primeira sessão, a equipa construiu um protótipo que, tendo revelado bons resultados, foi adaptado para as sessões seguintes. Novas sessões, e, por isso, novas estruturas e linguagens gráficas foram sendo desenhadas para responder a cada desafio proposto por cada escola e/ ou docente, visando responder às encomendas de conteúdos temáticos que nos foram feitas.

\subsubsection{Estrutura das sessões}

Construímos 4 estruturas-base de sessões que podem variar entre os 50 e os 150 minutos e cujos planeamento e respetivos desenvolvimentos se encontram detalhadamente descritos nos anexos 2 a 5, enunciando objetivos, conteúdos, dinâmicas e recursos usados. As estruturas das sessões são modelares, podendo ser editadas para qualquer contexto a fim de responder às especificidades de cada escola (tema, duração, curso e número de alunos).

\section{\#1 O olhar sociológico sobre o mundo}

A primeira sessão visou responder à chamada genérica da APS sobre "O olhar sociológico sobre o mundo" e estruturou-se em 5 partes que se relacionam: i) O que é a Sociologia?; ii) Como os sociólogos entendem o mundo?; iii) Temas de estudo da Sociologia; iv) O que fazem os sociólogos?; v) Estudar Sociologia. (anexo 2)

\section{\#2 Compreender o mundo com Sociologia}

Uma segunda sessão respondeu a um pedido específico de uma escola: investigação e intervenção sociológica. Esta estrutura manteve partes da primeira apresentação mas com dois novos enfoques: i) O que é a Sociologia?; ii) Como a Sociologia analisa a realidade social? iii) Temas de estudo da Sociologia; iv) Como intervir na realidade social com a Sociologia?; v) Estudar Sociologia. (anexo 3)

\section{\#3 Investigação nas Ciências Sociais}

A terceira sessão foi solicitada para turmas a frequentarem a disciplina de Sociologia e que pretendiam compreender melhor as potencialidades da investigação sociológica. As 4 partes repartiam-se nos seguintes temas: i) Ciências Sociais e Ciências Exatas; ii) Olhar sociológico; iii) Investigação sociológica; iv) Estudar Sociologia. (anexo 4) 


\section{\#4 Sociologia, relações sociais e emoções}

A última sessão respondeu a um pedido de uma escola que dinamizou uma semana de sensibilização às relações amorosas em tempos de pandemia, pretendendo que fossem abordados temas como o uso das redes sociais, a violência, o consumo online. Desta vez, dada a duração mais longa da sessão, esta foi estruturada em 6 partes: i) O que estuda a Sociologia?; ii) Redes sociais e consumo; iii) Invenção da juventude; iv) Novas comunicações, novas relações; v) Namoro em pandemia; vi) Estudar Sociologia (anexo 5).

\subsection{Estratégias pedagógicas: dinâmicas e recursos pedagógicos}

Todas as sessões foram feitas através de uma apresentação de slides composta por conceitos-chave, gráficos e imagens, que, muitas vezes, serviram de base para jogos e debates (por exemplo, deixando questões em aberto respondidas pelo slide seguinte). Todos os slides seguiram uma linguagem gráfica intuitiva e juvenil, com uma linguagem oral informal e descontraída, capaz de manter a atenção dos alunos durante toda a sessão. Em cada apresentação nova, os slides foram recriados para responder ao tema proposto (anexo 6 - o jogo das estatísticas e o jogo das posições).

A apresentação dos slides foi acompanhada por 4 dinâmicas práticas de ativação da participação dos estudantes:

\section{i) Questões abertas}

Sempre que possível, a equipa dinamizadora incentivava os alunos a comentarem as ideias pré-concebidas que tinham sobre um determinado tema. Num registo muito informal, esta dinâmica serve como uma abertura para aprofundar um tema em concreto, e para a equipa fazer um breve diagnóstico sobre a proximidade dos alunos à temática que será abordada.

\section{ii) Debates}

Através de um ponto de partida específico, como uma afirmação ou uma imagem, foi incentivado o debate entre os estudantes, de forma livre, mas organizada. Muitas vezes confrontados com uma questão concreta sobre a qual têm de se posicionar, os estudantes foram encorajados a partilhar, com a equipa e com os colegas, a sua opinião/conhecimento e os mecanismos que consideram importantes para que formulem uma e não outra convicção. Com frequência, recorreu-se ao número de mãos levantadas, a favor e contra, alguma afirmação ou imagem, para quebrar o gelo para a conversa. Destes debates, surgiram ideias concretas que serviram para concluí-los, seja sobre o conteúdo específico da conversa, seja sobre os motivos que suportam as representações sociais partilhadas.

\section{iii) Refletir com imagens}

A apresentação de imagens, como demonstração, exemplo, comparação e/ ou sugestão, foi uma técnica recorrente nestas sessões. As imagens escolhidas e 
trabalhadas de acordo com as temáticas e os conteúdos a transmitir permitiram criar sempre momentos de reflexão, onde se solicita aos alunos que comentem, descubram ou descrevam o que sentem.

\section{iv) Histórias com final aberto}

Para incentivar não só a participação, mas também a imaginação sociológica, criaram-se pequenas histórias temáticas que descrevem uma situação banal do quotidiano, interrompido com um imprevisto qualquer. A ideia desta estratégia é que sejam os alunos a completar esta história para que depois se possa discutir a natureza das suas escolhas e as semelhanças e diferenças entre a versão de cada um.

v) Jogos didáticos

Os jogos, de natureza diversa, não só funcionam como quebra-gelo, que ampliam a participação de todos os alunos, como também são usados para concretizar ideias-chave de um tema que se tenha discutido (anexo 6).

vi) A valiação

Todas as sessões foram avaliadas pelos alunos e pelos docentes que assistiram à sessão, não só com objetivos de monitorização e reflexão internas, mas também de melhoria contínua e adequação das diferentes sessões.

Do ponto de vista dos recursos mobilizados, ou seja, dos suportes usados para auxiliar as dinâmicas, salientam-se:

i) Recurso a imagens, com fotografias e vídeo

Os slides de base integram no seu seio: a) fotografias de situações e/ou pessoas sem legenda que são alvo de comentários e abrem debates sobre as formas como percecionamos os outros e o mundo; b) coleções de imagens relativas a um contex to social específico, de maneira a demonstrar modos de vida e práticas diferentes; c) imagens publicitárias para abrirem o debate sobre questões de representação e representatividade mediática; d) pequenos vídeos que funcionam como gatilhos para estimularem debates sobre temas concretos, que podem variar entre registos jornalísticos ou curtas-metragens.

ii) Folhetos desdobráveis

Todos os participantes da sessão receberam três folhetos: a) "Estudar Sociologia", folheto informativo sobre os programas curriculares da Licenciatura em Sociologia na FLUP e com esclarecimentos sucintos sobre a diversidade de papéis profissionais dos sociólogos; b) "Joga e Aprende", folheto didático com Sopa de Letras e Palavras Cruzadas relacionadas com a temática da Sociologia; c) "Um olhar sociológico sobre o mundo", folheto com um breve tex to sobre o olhar sociológico, e um mapa nacional com todas as ofertas universitárias da licenciatura em Sociologia. Todos os folhetos contêm vários contactos, institucionais e informais, a que os públicos são incentivados a recorrer com questões e notas. Esta distribuição de documentos ficou cancelada com a vivência da crise pandémica.

iii) Jornais e revistas 
Os meios de comunicação tradicionais, nomeadamente notícias e imagens de jornais e revistas, foram apresentados e partilhados como ponto de partida para debate, ao facilitarem o modo comum como retratam ou expõem algum caso, ideia ou conceito.

\section{Avaliação do projeto}

Várias foram as escolas secundárias que abriram as portas ao projeto, respondendo ao convite da APS e/ou da equipa líder de estudantes que implementava o projeto: visitámos 11 escolas e realizámos 30 sessões, abrangendo uma estimativa de 730 estudantes e 32 professores (anexo 1). Todas as sessões terminaram com a aplicação de inquéritos de avaliação preenchidos com o apoio da equipa dinamizadora, com exceção das sessões realizadas em 2021 em resultado das limitações de contacto em contex to de crise pandémica. Foram aplicados e respondidos 601 inquéritos. A avaliação foi entendida como técnica de aprendizagem que, pelo retorno recolhido junto dos dois públicos-alvo das ações, permitiu, a cada momento, mudar ou ajustar os conteúdos e as estratégias e corresponder, da melhor forma, àquilo que professores e estudantes esperavam das sessões.

\subsection{Avaliação aos olhos dos estudantes}

Algo importante para a equipa, desde o início do projeto, foi tornar as sessões um momento prazeroso e o mais participativo possível. Desta forma, percebe-se que as dinâmicas das sessões - debates sobre vários temas, interação existente, liberdade de expressão e jogos utilizados - são os aspetos considerados mais positivos por grande parte dos alunos (46,2\%). Seguem-se aqueles que gostaram de tudo $(16,1 \%)$ e os que destacam os conteúdos transmitidos $(14,1 \%)$ e os recursos utilizados $(11,5 \%)$. Um número considerável de estudantes (37\%) não respondeu à pergunta sobre o aspeto mais negativo da sessão, sendo que quase outros tantos $(32,1 \%)$ consideraram não haver nenhum momento da sessão que lhes desagradasse. Em detalhe, é possível acrescentar que, dos alunos que apontaram aspetos desfavoráveis (11\%), estes referem-se a fatores externos ao projeto, como barulho na sala e comentários desajustados por parte dos participantes.

\subsection{Avaliação aos olhos dos professores}

Uma das grandes aprendizagens para a equipa líder de estudantes foi a mediação requerida durante as sessões, não só entre os alunos mas também entre estes e os docentes quando houve momentos de tensão, decorrentes dos debates e jogos dinamizados na sessão. Com alguma frequência, e no seguimento dos 
objetivos da APS ao lançar este programa, os alunos expressaram sentir-se mais confortáveis para partilharem a sua opinião durante estas sessões do que durante as aulas, o que suscitou momentos de desconforto para alguns docentes, nomeadamente durante os debates sobre as desigualdades na educação. No entanto, a maioria dos docentes manifestou uma atitude muito colaborativa e interessada, tendo contribuído para incentivar os alunos a participarem, alertando-os para a importância deste tipo de sessões nas escolas, que ajudam a consolidar conhecimentos transmitidos mais verticalmente nas aulas. Esta recetividade dos docentes às sessões torna-se clara quando é tão elevada a sua concordância face à importância dos conteúdos abordados $(96,5 \%)$, à pertinência dos recursos escolhidos $(85,7 \%)$ e quanto ao facto de a interação ter sido motivadora $(82,2 \%)$.

Sobre os objetivos das sessões, foram elevadas as taxas de concordância com o esclarecimento concetual sobre a Sociologia $(85,8 \%)$ e a transmissão de uma visão prática da disciplina $(85,7 \%)$. No entanto, estes valores diminuem para três quartos $(75 \%)$ quando são relativos ao esclarecimento dos papéis profissionais dos sociólogos, o que corresponde a uma dificuldade sentida pela equipa: como transmitir de forma concreta o que é a Sociologia e a diversidade de papéis profissionais de um sociólogo? Para fazer face a esta necessidade, a equipa sugeriu à APS a criação de um vídeo informativo ${ }^{5}$ que tratasse as questões profissionais da disciplina e que reunisse um conjunto de testemunhos profissionais de licenciados e mestres em Sociologia. Esse pedido foi bem recebido, não só pela sua pertinência, mas também por se alinhar com uma vontade que a própria APS já tinha. No futuro espera-se que este vídeo informativo seja um recurso pedagógico distribuído entre os docentes do ensino secundário. Este, sendo enviado previamente para as escolas e visualizado antes das datas das sessões presenciais, pode facilitar o contacto com a disciplina ao desenvolver três grandes áreas: formação, profissionalização e definição/conceptualização da Sociologia como ciência.

Além da avaliação quantitativa por via dos inquéritos, a equipa tem feito sempre um registo qualitativo das sessões, que advém das conversas no final das mesmas, onde vários alunos e docentes se demoram a sair da sala e comentam as suas impressões. Nessas conversas, e mesmo em e-mails subsequentes à presença da equipa nas escolas, é possível constatar que o interesse neste tipo de atividades é muito grande e que há um grande apreço pela educação de pares, tanto pelos alunos que aproveitam para conhecer os trajetos pessoais e universitários dos elementos da equipa, como por parte dos docentes que veem aqui uma oportunidade de reforçar para as suas turmas, e com maior descontração, a importância da via universitária.

5 Sociologia em ação: modos de ver e de fazer sociologia em Portugal", concluído em março de 2021 e disponível em https://www.youtube.com/watch?v=U0B1ysDww5U. Consultado, pela última vez, a 9/04/2021. 


\subsection{A avaliação aos olhos da equipa líder do projeto: o exercício do ofício pelos aprendizes entre portas da Universidade}

Como equipa líder do projeto, os inquéritos de avaliação e a conversa com estudantes e professores permitem perceber o que falha no projeto, os pontos fortes e os pontos fracos das sessões. Embora a avaliação seja um processo formal, existiu sempre na equipa uma dinâmica coletiva informal, de modo a colocar todos os elementos a par do que ia acontecendo nas diferentes sessões. Houve, por isso, uma autoavaliação das sessões em espaço de reuniões coletivas entre os membros da equipa para discutir as sessões ocorridas, refletir sobre algum momento menos bom, procurar soluções para não cometer os mesmos erros em sessões futuras: têm sido muitas horas de trabalho conjunto, discussão, indecisão e treino da exposição oral sobre a melhor forma de transmitir os conteúdos.

Esta constante procura de evolução do trabalho em equipa, que fortalece a relação entre pares, são duas das grandes vantagens do projeto. Ademais, o projeto conseguiu influenciar de forma positiva o desempenho académico da equipa líder e dos seus membros, nomeadamente a confiança e descontração em apresentações de trabalhos para as unidades curriculares e, também, o domínio e a reflexão sobre as temáticas focadas, muitas vezes lecionadas na sala de aula da Licenciatura em Sociologia: "Levamos da nossa sala de aula para a sala de aula do secundário". Para além disso, aumentou o capital social entre os estudantes, criou laços fortes e, como sociólogas e sociólogos ou aprendizes do ofício, permitiu pôr em prática as teorias aprendidas ao longo dos vários anos de presença no ensino superior, como por exemplo, o conceito de solidariedade orgânica associado à divisão do trabalho no interior da equipa ou de mediação de situações entre professores e estudantes do ensino secundário.

Nem sempre os temas foram bem recebidos e o tema que mais discórdia causou foi o das desigualdades na educação, como já referido. Na sua abordagem, sentimos que enquanto alguns alunos se reveem na temática e estão a ser ouvidos, alguns professores reagem com uma postura defensiva. A capacidade de mediar este tipo de situações foi também uma competência apurada durante o projeto. Nas sessões, a equipa de projeto assumiu um papel constante de mediação face aos conflitos emergentes entre os grupos de estudantes do ensino secundário aquando da discussão dos temas propostos.

O desafio de cada sessão causava algum incómodo, mas logo se traduzia numa aprendizagem pela prática (Schon, 1987), como se pode ler no testemunho de um dos membros da equipa de trabalho:

Deve relevar-se a importância do contacto com as plateias compostas por gerações mais jovens, uma vez que, da mesma forma que vamos às apresentações para ensinar e fazer refletir, a natureza informal e de debate 
que mantemos nas apresentações permite, a quem apresenta, aprender e auscultar as inquietações, problemáticas e interesses das populações com quem contactam. Não foram poucas as vezes em que saímos das apresentações inquietados ou maravilhados com alguma intervenção de um dos miúdos, que nos puseram a pensar e a ponderar novas abordagens e conteúdos [Membro da equipa].

Outro desafio enfrentado em todas as sessões remete para o esforço quanto à linguagem: usar um vocabulário neutro, medindo as palavras e a própria caracterização dos contornos das temáticas, para que alunos e professores não sentissem que estávamos a emitir juízos sobre as suas atitudes e comportamentos. Sendo um dos objetivos do projeto contribuir para a sensibilização das questões societais, cidadania e tolerância, promover a participação porque estavam num lugar seguro de partilha de opiniões era algo a garantir aos jovens.

Destaque evidenciado nestas sessões é a falta de formação de base em Sociologia nos professores que lecionam a disciplina no ensino secundário. Tal mostra que ainda há um longo caminho a percorrer na promoção da inserção de sociólogos e da própria Sociologia enquanto ciência social no ensino secundário.

Por último, a Covid-19 tem sido um desafio, não só porque nos impede de visitar as escolas, como alterou a dinâmica em sala de aula, refletindo-se numa maior rigidez na comunicação, pela vigilância constante em manter o distanciamento dos alunos e em não poder partilhar com os estudantes do ensino secundário materiais pedagógicos. Por esse mesmo efeito, nas sessões que decorreram durante a crise pandémica Covid-19, não foi possível distribuir os folhetos e os inquéritos. Em alternativa, construiu-se um inquérito online que chegou a ser divulgado, mas sem sucesso, porque nenhuma resposta foi submetida. Os docentes que divulgaram o inquérito avisaram-nos desta possibilidade, porque não sendo um material de preenchimento obrigatório e sem o auxílio que outrora se dava em sala de aula, é mais fácil que seja um investimento esquecido ou ignorado por parte dos alunos.

\section{Reflexões finais}

Este projeto trouxe valências e oportunidades inesperadas a todos os membros da equipa. Por um lado, tem sido um espaço de aplicação e operacionalização de conceitos (e mesmo práticas) sociológicas, numa tentativa contínua de “aprender para ensinar". A oportunidade de desconstruir e simplificar a disciplina sociológica tem tido resultados positivos no aproveitamento académico de todos os intervenientes, uma vez que auxilia a consolidação dos ensinamentos trazidos das salas universitárias. Este aproveitamento não é apenas na 
compreensão das teorias, mas também nas valências comunicacionais, visto que exige de toda a equipa uma postura de interação. A própria frequência das sessões e a intensidade das suas preparações têm contribuído para que os membros da equipa se inteirem acerca das saídas profissionais e temáticas da Sociologia, auxiliando as suas decisões universitárias e pós-universitárias.

O trabalho em equipa tem servido "para garantir que todos os intervenientes têm a oportunidade de participar, na mesm a medida, na criação, adaptação e concretização das ideias e tarefas, assim como assegura a distribuição das responsabilidades, garantindo que ninguém fica sobrecarregado" [membro da equipa]. O esforço coletivo e a dedicação dada a este projeto, quer pelos alunos que o integram, quer pelas professoras que sempre o divulgaram e monitoraram, foram a chave de sucesso para u ma boa atmosfera e sucesso no trabalho de equipa.

Do ponto de vista da interação entre professores universitários e aprendizes da Sociologia, o projeto condu ziu a u ma aproximação geracional e significativa ao longo dosanos. Desdeo planeamento à concretização do plano de projeto, o esforço e exultação permitiram um crescimento pessoal e profissional de a mbas as partes.

A continuidade e a solidificação do projeto têm vindo a ser asseguradas pela construção de um modelo de fácil replicabilidade, em que os elementos mais novos da equipa rapidamente se inteiram de todo o processo, uma vez que, internamente, há acesso a todos os materiais disponíveis, organizados e atualizados, juntamente com um manual orientador. Para além disso, espera-se que este projeto seja maior do que a equipa líder que o fundou e que continue a ser promovido pela APS, dada a garantia de financiamento indispensável para a sua manutenção e promoção. Espera-se, também, que outras universidades o queiram e consigam replicar, de forma a possibilitar a constituição de parcerias com outras equipas que desempenhem o mesmo papel noutras zonas do país. Em 2019, recebemos um convite para um dos elementos da equipa coordenar um work shop na Universidade da Beira Interior, de modo a transmitir modelos que pudessem ser replicados por novas equipas de estudantes universitários.

Existem também algumas reflexões quanto às escolas secundárias e às várias sessões. A primeira remete para os próximos meses/anos de adaptação e reajustamento das sessões devido à Covid-19. A título exemplificativo, não só existe um maior número de regras, como pode haver uma diminuição do número de sessões. Uma outra passa por entender que embora as sessões sejam bem vistas pelos alunos, estes muitas vezes não pretendem realizar a sua formação superior em Sociologia. Assim, conseguimos perceber que ainda existe um longo percurso de todos os sociólogos, da própria sociedade e instituições em mostrar a importância da Sociologia, das Ciências Sociais e do seu valor enquanto área científica e de intervenção socioeconómica.

Ademais, um apontamento que merece ser reforçado é a pertinência destes projetos em alertar para o longo debate sobre a falta de profissionais formados em Sociologia a lecionar a disciplina, o que é um ponto sempre denunciado nas 
apresentações. Sendo verdade que o projeto dá visibilidade e esclarecimento sobre a ciência social aos mais jovens, também é verdade a observação da necessidade de mais espaço para profissionais de Sociologia, dentro das instituições secundárias. Por último, e enquanto equipa-líder, deixamos o nosso agradecimento à APS e a todos os novos membros que contribuíram e que, esperamos, continuem a contribuir no futuro para a implementação do projeto. Congratulamo-nos, professoras e alunas que o liderámos, por o narrarmos agora sob a forma de artigo, com a oportunidade de responder aos desafios da explicitação e da consolidação da Sociologia como ciência e profissão, o que permitiu que, em papéis diferentes, todas crescêssemos, académica e pessoalmente.

\section{Referências bibliográficas}

ALMEIDA, João Ferreira de - Sessão Comemorativa dos 20 anos da A PS [em linha]. [consult. 15 fev. 2021]. Disponível em: https://aps.pt/pt/historia-da-aps/.

AUSUBEL, D. P. A - Aprendizagem Significativa: a teoria de David A usubel. São Paulo: Moraes, 1982. ISBN 8-5882-0824-5.

COM ISSÃO EUROPEIA - Education and Training [em linha]. Bruxelas: Comissão Europeia. 2021 [consult. 09 abr. 2021]. Disponível em: https://ec.europa.eu/education/education-in-the-eu/ about-education-and-training-in-the-eu_pt.

FREIRE, Paulo - Pedagogia da A utonomia: saberes necessários à prática educativa. São Paulo: Paz e Terra, 1996. ISBN 978-85-7753-163-9.

JIN KINGS, Nise - Ensino de Sociologia: particularidades e desafios contemporâneos. Revista Mediações. Setúbal. ISSN 2176-6665. 12:1 (2007), p. 113-130.

LAHIRE, Bernard - Viver e interpretar o mundo social: para que serve o ensino da Sociologia? Revista de Ciências Sociais. Fortaleza. ISSN 2318-4620. 45: 1 (2014), p. 45-61.

MARTINS, Rogéria da Silva; FRAGA, Paulo Cesar Pontes - Ensino de Sociologia na França, Portugal e Brasil: uma perspectiva comparada diante das idiossincrasias da reforma do Ensino Médio brasileiro. Latitude. Maceió. ISSN 2179-5428. 15: edição especial (2021), p. 161-188.

NEUHOLD, R. dos Reis (2013) - Notas sobre a história da sociologia no ensino secundário de Portugal - Revista Brasileira de Sociologia. Rio Grande do Sul. ISN N 2317-8507. 1: 2 (2012), p. 131-146.

SCHÖN, D. A. - Jossey-Bass higher education series. Educating the reflective practitioner: Toward a new design for teaching and learning in the professions. San Francisco: JosseyBass Publishers, 1987. ISBN 978-15-5542-220-2.

YOUTUBE - Sociologia em Ação: modos de ver e de fazer sociologia em Portugal [em linha]. [consult. abr. 2021]. Disponível em: https://ww w.youtube.com/watch?v=U0B1ysDww5U.

SVENSON, R. Gary (eds.) - European guidelines for youth AIDS peer education. Sweden: Europeer, 1988.

UP - Universidade do Porto [em linha]. Porto: Universidade do Porto. 2021. [consult. 09 abr. 2021]. Disponível em: https://sigarra.up.pt/up/pt/.

- Receção: 16.05.2021

- Aprovação: 20.07.2021 
Anexo 1 - Escolas Secundárias visitadas por região

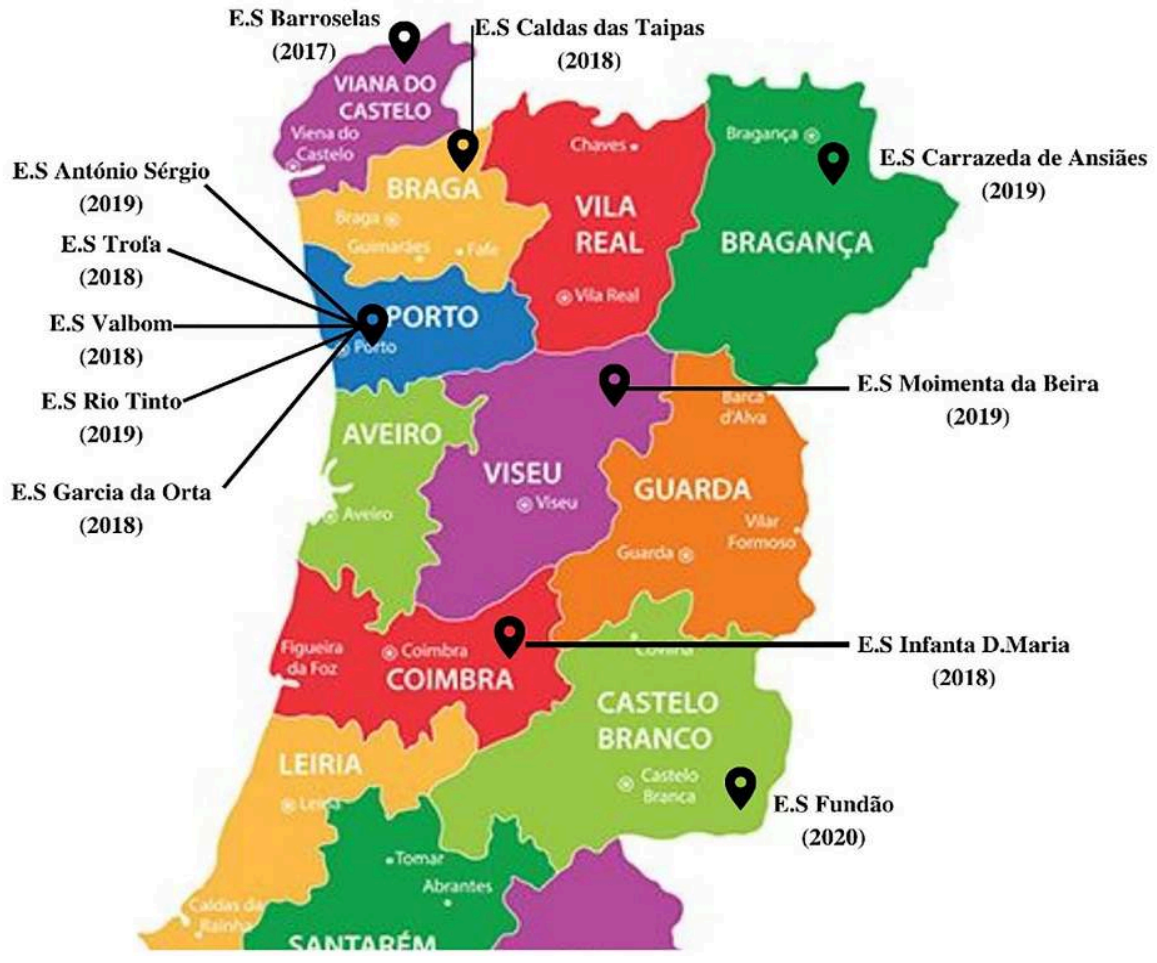


Anexo 2 - Estrutura da sessão: “O olhar sociológico sobre o mundo

\begin{tabular}{|c|c|c|c|c|c|}
\hline \multicolumn{6}{|c|}{ APRESENTAÇÃO N.'1 - 0 OLHAR SOCIOLÓGICO SOBRE 0 MUND0 } \\
\hline & $\begin{array}{l}0 \text { que é a } \\
\text { Sociologia? }\end{array}$ & $\begin{array}{l}\text { Como os } \\
\text { sociólogos } \\
\text { entendem } 0 \\
\text { mundo? } \\
\end{array}$ & $\begin{array}{l}\text { Temas de } \\
\text { estudo da } \\
\text { Sociologia }\end{array}$ & $\begin{array}{l}0 \text { que fazem os } \\
\text { sociólogos? }\end{array}$ & $\begin{array}{l}\text { Estudar } \\
\text { Sociologia }\end{array}$ \\
\hline Objetivos & $\begin{array}{l}\text { Dar a conhecer a } \\
\text { Sociologia }\end{array}$ & $\begin{array}{l}\text { Demonstrar } \\
\text { como os } \\
\text { sociólogos } \\
\text { percecionam os } \\
\text { fenómenos } \\
\text { sociais }\end{array}$ & $\begin{array}{l}\text { Apresentar } \\
\text { temáticas sobre } \\
\text { as quais a } \\
\text { Sociologia se } \\
\text { debruça } \\
\text { regularmente }\end{array}$ & $\begin{array}{l}\text { Divulgar papéis } \\
\text { e perfis } \\
\text { profissionais } \\
\text { dos sociólogos } \\
\text { Divulgar } \\
\text { propostas de } \\
\text { transformação } \\
\text { social }\end{array}$ & $\begin{array}{l}\text { Informar sobre } \\
\text { as ofertas e } \\
\text { requisitos do } \\
\text { acesso à } \\
\text { formação } \\
\text { superior em } \\
\text { Sociologia e } \\
\text { sobre as } \\
\text { formações pré- } \\
\text { universitárias }\end{array}$ \\
\hline Conteúdos & $\begin{array}{l}\text { Conceito de } \\
\text { ciência social } \\
\text { Objeto de estudo } \\
\text { da Sociologia } \\
\text { Objetivos e } \\
\text { potencialidades } \\
\text { da Sociologia }\end{array}$ & $\begin{array}{l}\text { Conhecimento } \\
\text { do senso } \\
\text { comum/ } \\
\text { conhecimento } \\
\text { científico } \\
\text { Representação } \\
\text { social sobre o } \\
\text { desvio e } \\
\text { formação de } \\
\text { estereótipos }\end{array}$ & $\begin{array}{l}\begin{array}{l}\text { Conceito de } \\
\text { desigualdade } \\
\text { social }\end{array} \\
\text { Desigualdades } \\
\text { na educação } \\
\text { Questões sobre } \\
\text { o conceito } \\
\text { relativo de } \\
\text { educação } \\
\text { Dados } \\
\text { estatísticos } \\
\text { sobre } \\
\text { desigualdades } \\
\text { na educação }\end{array}$ & $\begin{array}{l}\text { Diferentes áreas } \\
\text { e serviços onde } \\
\text { os sociólogos } \\
\text { atuam }\end{array}$ & $\begin{array}{l}\text { Distribuição } \\
\text { geográfica da } \\
\text { licenciatura em } \\
\text { Sociologia } \\
\text { (Portugal e } \\
\text { Ilhas) } \\
\text { Oferta de } \\
\text { experiências } \\
\text { pré- } \\
\text { universitárias } \\
\text { em Sociologia }\end{array}$ \\
\hline Dinâmicas & $\begin{array}{l}\text { Questões abertas } \\
\text { Exposição de } \\
\text { conceitos }\end{array}$ & 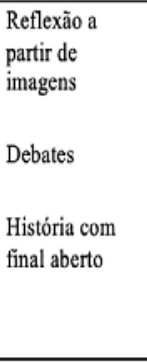 & $\begin{array}{l}\text { Jogo das } \\
\text { estatísticas } \\
\text { História com } \\
\text { final aberto } \\
\\
\text { Jogo do } \\
\text { verdadeiro e } \\
\text { falso }\end{array}$ & $\begin{array}{l}\text { Questões } \\
\text { abertas } \\
\text { Exposição de } \\
\text { perfis } \\
\text { profissionais }\end{array}$ & $\begin{array}{l}\text { Partilha de } \\
\text { experiências } \\
\text { universitárias } \\
\text { dos } \\
\text { dinamizadores } \\
\text { Conversa mais } \\
\text { informal sobre } \\
\text { os trajetos que } \\
\text { os estudantes } \\
\text { esperam seguir }\end{array}$ \\
\hline Recursos & $\begin{array}{l}\text { Apresentação } \\
\text { visual - uso de } \\
\text { slides }\end{array}$ & $\begin{array}{l}\text { Apresentação } \\
\text { visual - uso de } \\
\text { slides }\end{array}$ & $\begin{array}{l}\begin{array}{l}\text { Apresentação } \\
\text { visual - uso de } \\
\text { slides }\end{array} \\
\text { Recortes de } \\
\text { jornais e } \\
\text { revistas } \\
\text { Jogo impresso } \\
\text { em PVC }\end{array}$ & $\begin{array}{l}\text { Apresentação } \\
\text { visual - uso de } \\
\text { slides }\end{array}$ & 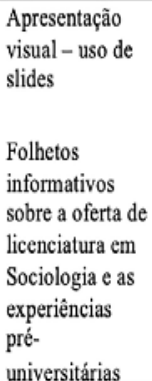 \\
\hline
\end{tabular}


Anexo 3 - Estrutura da sessão: “Compreender o mundo com a Sociologia”

\begin{tabular}{|c|c|c|c|c|c|}
\hline \multicolumn{6}{|c|}{ APRESENTAÇÃO N.² - COMPREENDER O MUNDO COM SOCIOLOGIA } \\
\hline & $\begin{array}{l}\text { O que é a } \\
\text { Sociologia? }\end{array}$ & $\begin{array}{l}\text { Como a } \\
\text { Sociologia } \\
\text { analisa a } \\
\text { realidade social? }\end{array}$ & $\begin{array}{l}\text { Temas de estudo } \\
\text { da Sociologia }\end{array}$ & $\begin{array}{l}\text { Como intervir } \\
\text { na realidade } \\
\text { social com a } \\
\text { Sociologia? }\end{array}$ & $\begin{array}{l}\text { Estudar } \\
\text { Sociologia }\end{array}$ \\
\hline Objetivos & $\begin{array}{l}\text { Dar a conhecer } \\
\text { a Sociologia }\end{array}$ & $\begin{array}{l}\text { Demonstrar } \\
\text { técnicas de análise } \\
\text { e compreensão } \\
\text { sociológica sobre } \\
\text { a realidade }\end{array}$ & $\begin{array}{l}\text { Apresentar } \\
\text { temáticas sobre as } \\
\text { quais a Sociologia } \\
\text { se debruça } \\
\text { regularmente }\end{array}$ & $\begin{array}{l}\text { Divulgar } \\
\text { propostas de } \\
\text { transformação } \\
\text { social }\end{array}$ & $\begin{array}{l}\text { Informar sobre as } \\
\text { ofertas e } \\
\text { requisitos do } \\
\text { acesso à formação } \\
\text { superior em } \\
\text { Sociologia e sobre } \\
\text { as formações pré- } \\
\text { universitárias }\end{array}$ \\
\hline Conteúdos & $\begin{array}{l}\begin{array}{l}\text { Conceito de } \\
\text { ciência social }\end{array} \\
\text { Objeto de } \\
\text { estudo da } \\
\text { Sociologia } \\
\text { Objetivos e } \\
\text { potencialidade } \\
\text { s da Sociologia }\end{array}$ & 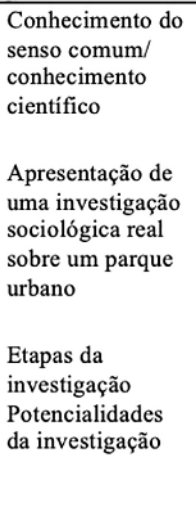 & $\begin{array}{l}\begin{array}{l}\text { Conceito de } \\
\text { desigualdade } \\
\text { social }\end{array} \\
\begin{array}{l}\text { Desigualdades } \\
\text { económicas }\end{array} \\
\begin{array}{l}\text { Desigualdades na } \\
\text { saúde }\end{array} \\
\text { Desigualdades } \\
\text { étnico-raciais } \\
\text { Desigualdades de } \\
\text { género }\end{array}$ & 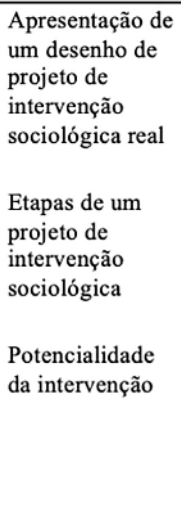 & $\begin{array}{l}\text { Distribuição } \\
\text { geográfica da } \\
\text { licenciatura em } \\
\text { Sociologia } \\
\text { (Portugal e Ilhas) } \\
\text { Oferta de } \\
\text { experiências pré- } \\
\text { universitárias em } \\
\text { Sociologia }\end{array}$ \\
\hline Dinâmicas & $\begin{array}{l}\text { Questões } \\
\text { abertas } \\
\begin{array}{l}\text { Exposição de } \\
\text { conceitos }\end{array}\end{array}$ & 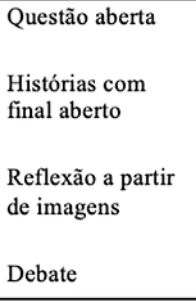 & 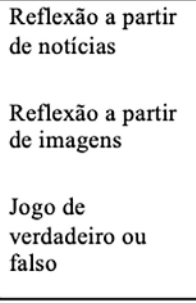 & $\begin{array}{l}\text { Questões } \\
\text { abertas }\end{array}$ & $\begin{array}{l}\text { Partilha de } \\
\text { experiências } \\
\text { universitárias dos } \\
\text { dinamizadores }\end{array}$ \\
\hline Recursos & $\begin{array}{l}\begin{array}{l}\text { Apresentação } \\
\text { visual - uso de } \\
\text { slides }\end{array} \\
\text { Folheto } \\
\text { informativo } \\
\text { sobre a } \\
\text { sociologia com } \\
\text { palavras } \\
\text { cruzadas e } \\
\text { sopa de letras }\end{array}$ & $\begin{array}{l}\text { Apresentação } \\
\text { visual - uso de } \\
\text { slides }\end{array}$ & 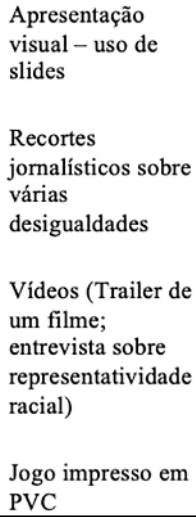 & $\begin{array}{l}\text { Apresentação } \\
\text { visual - uso de } \\
\text { slides }\end{array}$ & $\begin{array}{l}\text { Folhetos } \\
\text { informativos } \\
\text { sobre a oferta de } \\
\text { licenciatura em } \\
\text { Sociologia e as } \\
\text { experiências pré- } \\
\text { universitárias }\end{array}$ \\
\hline
\end{tabular}


Anexo 4 - Estrutura da sessão: "Investigação nas Ciências Sociais"

\begin{tabular}{|c|c|c|c|c|}
\hline \multicolumn{5}{|c|}{ APRESENTAÇÃO N. ${ }^{\circ} 3$ - INVESTIGAÇÃO NAS CIÊNCIAS SOCIAIS } \\
\hline & $\begin{array}{l}\text { Ciências Sociais e } \\
\text { Ciências Exatas }\end{array}$ & Olhar sociológico & Investigação sociológica & $\begin{array}{l}\text { Estudar } \\
\text { Sociologia }\end{array}$ \\
\hline Objetivos & $\begin{array}{l}\text { Explicar as } \\
\text { diferenças e } \\
\text { semelhanças entre } \\
\text { as ciências sociais } \\
\text { e as ciências } \\
\text { exatas }\end{array}$ & $\begin{array}{l}\text { Dar a conhecer as } \\
\text { possibilidades e } \\
\text { contornos do olhar } \\
\text { sociológico }\end{array}$ & $\begin{array}{l}\text { Demonstrar técnicas de } \\
\text { análise e compreensão } \\
\text { sociológica sobre a } \\
\text { realidade }\end{array}$ & $\begin{array}{l}\text { Informar sobre as } \\
\text { ofertas e } \\
\text { requisitos do } \\
\text { acesso à formação } \\
\text { superior em } \\
\text { Sociologia e sobre } \\
\text { as formações pré- } \\
\text { universitárias }\end{array}$ \\
\hline Conteúdos & $\begin{array}{l}\text { Conceito e } \\
\text { exemplos de } \\
\text { ciências sociais } \\
\text { Conceito e } \\
\text { exemplos de } \\
\text { ciências exatas } \\
\text { Conhecimento do } \\
\text { senso comum/ } \\
\text { conhecimento } \\
\text { cientifico }\end{array}$ & $\begin{array}{l}\text { Niveis de análise } \\
\text { Objeto de estudo da } \\
\text { Sociologia } \\
\text { Objetivos e } \\
\text { potencialidades da } \\
\text { Sociologia } \\
\text { Imaginação sociológica }\end{array}$ & $\begin{array}{l}\text { Método qualitativo/ } \\
\text { quantitativo } \\
\text { Etapas da investigação } \\
\text { sociológica } \\
\text { Apresentação de uma } \\
\text { investigação sociológica } \\
\text { sobre a profissão } \\
\text { "Youtuber" }\end{array}$ & $\begin{array}{l}\text { Distribuição } \\
\text { geográfica da } \\
\text { licenciatura em } \\
\text { Sociologia } \\
\text { (Portugal e Ilhas) } \\
\text { Oferta de } \\
\text { experiências pré- } \\
\text { universitárias em } \\
\text { Sociologia }\end{array}$ \\
\hline Dinâmicas & $\begin{array}{l}\text { Questões abertas } \\
\text { Exposição de } \\
\text { conceitos }\end{array}$ & $\begin{array}{l}\text { Questão aberta } \\
\text { Histórias com final } \\
\text { aberto } \\
\text { Reflexão a partir de } \\
\text { imagens }\end{array}$ & $\begin{array}{l}\text { Questões abertas } \\
\text { Reflexão a partir de } \\
\text { imagens } \\
\text { Exercício de investigação: } \\
\text { a partir da apresentação } \\
\text { de um estudo sobre os } \\
\text { problemas das redes } \\
\text { sociais na vida dos } \\
\text { jovens, os alunos } \\
\text { desenham em conjunto as } \\
\text { etapas de investigação } \\
\text { que fariam no estudo } \\
\text { deste fenómeno }\end{array}$ & $\begin{array}{l}\text { Partilha de } \\
\text { experiências } \\
\text { universitárias dos } \\
\text { dinamizadores } \\
\text { Conversa mais } \\
\text { informal sobre os } \\
\text { trajetos que os } \\
\text { estudantes } \\
\text { esperam seguir }\end{array}$ \\
\hline Recursos & $\begin{array}{l}\text { Apresentação } \\
\text { visual - uso de } \\
\text { slides }\end{array}$ & $\begin{array}{l}\text { Apresentação visual - } \\
\text { uso de slides }\end{array}$ & $\begin{array}{l}\text { Apresentação visual - uso } \\
\text { de slides } \\
\text { Recortes jornalísticos } \\
\text { Vídeos } \\
\text { Jogo em PVC }\end{array}$ & $\begin{array}{l}\text { Folhetos } \\
\text { informativos } \\
\text { sobre a oferta de } \\
\text { licenciatura em } \\
\text { Sociologia e as } \\
\text { experiências pré- } \\
\text { universitárias }\end{array}$ \\
\hline
\end{tabular}


Anexo 5 - Estrutura da sessão: "Sociologia, relações sociais e emoções"

\begin{tabular}{|c|c|c|c|c|c|c|}
\hline \multicolumn{7}{|c|}{ APRESENTACุÁO N."4 - SOCIOLOGIA, RELAC COES SOCIAIS E EMOCৃOES } \\
\hline & $\begin{array}{l}\text { O que estuda } \\
\text { a Sociologis? }\end{array}$ & $\begin{array}{l}\text { Reder rociais } \\
\text { e consumo }\end{array}$ & $\begin{array}{l}\text { Invençlio da } \\
\text { juventude }\end{array}$ & $\begin{array}{l}\text { Novas } \\
\text { comanicaçbesn } \\
\text { ovas relacdes }\end{array}$ & $\begin{array}{l}\text { Namoro om } \\
\text { pandemia }\end{array}$ & $\begin{array}{l}\text { Estudar } \\
\text { Sociologia }\end{array}$ \\
\hline Objetives & $\begin{array}{l}\text { Dar a } \\
\text { conbecer a } \\
\text { Sociologia }\end{array}$ & $\begin{array}{l}\text { Refletir sobre } \\
\text { a centralidade } \\
\text { das redes } \\
\text { sociais em } \\
\text { sodas as } \\
\text { escolhas dos } \\
\text { cousrumidores }\end{array}$ & $\begin{array}{l}\text { Demonstrar } \\
\text { como a } \\
\text { juventode é } \\
\text { também } \\
\text { socialmense } \\
\text { cousitruida }\end{array}$ & $\begin{array}{l}\text { Informar sobre } \\
\text { as dinamicas } \\
\text { sociais qae } \\
\text { decorrem das } \\
\text { aovas } \\
\text { tecnologias }\end{array}$ & $\begin{array}{l}\text { Questionar as } \\
\text { mudanças nas } \\
\text { relaçbes } \\
\text { aunorosas } \\
\text { entre os } \\
\text { jovens após a } \\
\text { Covid-19 }\end{array}$ & $\begin{array}{l}\text { Informar } \\
\text { sobre as } \\
\text { ofertas e } \\
\text { requisitos } \\
\text { do acesso à } \\
\text { fonnaçầ } \\
\text { superior em } \\
\text { Sociologia e } \\
\text { sobre as } \\
\text { fonnaçètes } \\
\text { pré- } \\
\text { universitziria } \\
\text { s }\end{array}$ \\
\hline Contetdidos & $\begin{array}{l}\text { Objeio de } \\
\text { estudo da } \\
\text { Seciologia } \\
\text { Questîes } \\
\text { sociológicas } \\
\text { Seciologia das } \\
\text { emopóes } \\
\text { Modernidade } \\
\text { e amor } \\
\text { solidaliquido }\end{array}$ & $\begin{array}{l}\text { Sociologia do } \\
\text { coussumo } \\
\text { Consumo } \\
\text { ensocional/ } \\
\text { comsumo } \\
\text { juvenil } \\
\text { Conceito } \\
\text { comercial da } \\
\text { felicidade } \\
\text { Apresentaçầo } \\
\text { de uma } \\
\text { investigaçào } \\
\text { sociologica } \\
\text { sobre a } \\
\text { profíssầo } \\
\text { "Youtuber" }\end{array}$ & $\begin{array}{l}\text { Conceito de } \\
\text { juventode e } \\
\text { invençio de } \\
\text { juventude } \\
\text { Represseatacio } \\
\text { mediática e } \\
\text { artística da } \\
\text { adolesclucia }\end{array}$ & 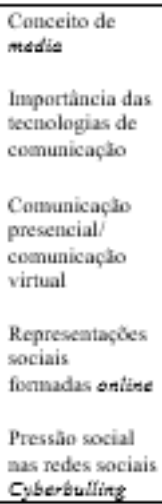 & $\begin{array}{l}\text { Mudanças nas } \\
\text { relaçbes } \\
\text { amorosas ao } \\
\text { longo do } \\
\text { tempo } \\
\text { Relaçöes } \\
\text { sociais e } \\
\text { distancianneat } \\
\text { o provocado } \\
\text { pela Covid-19 } \\
\text { Violència no } \\
\text { aamoro }\end{array}$ & $\begin{array}{l}\text { Distribuiçăo } \\
\text { geogrnifica } \\
\text { da } \\
\text { liceaciatura } \\
\text { en } \\
\text { Sociologia } \\
\text { (Portugal e } \\
\text { llhas) } \\
\text { Oferta de } \\
\text { experièncias } \\
\text { pré- } \\
\text { universitzára } \\
\text { s em } \\
\text { Sociologia }\end{array}$ \\
\hline Dinsmicas & $\begin{array}{l}\text { Quesilies } \\
\text { abertas } \\
\text { Exposichà de } \\
\text { cosceitos } \\
\text { Joge das } \\
\text { estatisticas } \\
\text { sobre } \\
\text { expectativas } \\
\text { de uma dating } \\
\text { spy }\end{array}$ & $\begin{array}{l}\text { Questalo } \\
\text { aberta } \\
\text { Reflexhlo a } \\
\text { partir de } \\
\text { imagens }\end{array}$ & $\begin{array}{l}\text { Reflecio a } \\
\text { partir de } \\
\text { imagens. }\end{array}$ & $\begin{array}{l}\text { Questîes } \\
\text { abertas } \\
\text { Jogo das } \\
\text { coocondincias } \\
\text { sobre comunicar } \\
\text { virtualneate } \\
\text { Jogos das } \\
\text { estatisticas } \\
\text { sobre } \\
\text { syberbutling }\end{array}$ & $\begin{array}{l}\text { Questîes } \\
\text { abertas } \\
\text { Reflecio a } \\
\text { partir de } \\
\text { imagens } \\
\text { Debate }\end{array}$ & $\begin{array}{l}\text { Partilha de } \\
\text { experiencias } \\
\text { universitziria } \\
\text { s dos } \\
\text { dinamizadoe } \\
\text { es } \\
\text { Conversa } \\
\text { mais } \\
\text { informal } \\
\text { sobre os } \\
\text { trajesos que } \\
\text { os } \\
\text { estudantes } \\
\text { esperam } \\
\text { sescuir }\end{array}$ \\
\hline Recursos & $\begin{array}{l}\text { Apresentaçào } \\
\text { visual - use } \\
\text { de slides } \\
\text { Folheto } \\
\text { informativo } \\
\text { sobre a } \\
\text { sociologia } \\
\text { com Palavras } \\
\text { Cruzadas e } \\
\text { Sepa de } \\
\text { Letras }\end{array}$ & $\begin{array}{l}\text { Apresentaçầo } \\
\text { visual - uso } \\
\text { de slídes } \\
\text { Apresentaçầo } \\
\text { de uma } \\
\text { música }\end{array}$ & $\begin{array}{l}\text { Apresentaçäo } \\
\text { visual - uso } \\
\text { de slides } \\
\text { Apresentaçào } \\
\text { de postders de } \\
\text { filmes juvenis } \\
\text { de } 1950 \text { a } \\
2020 .\end{array}$ & $\begin{array}{l}\text { Apresentaçâo } \\
\text { visual - uso de } \\
\text { sfides } \\
\text { Curta-metragem } \\
\text { sobre a pressio } \\
\text { de manter uma } \\
\text { vida social ativa } \\
\text { ovelíte }\end{array}$ & $\begin{array}{l}\text { Apresentaçâo } \\
\text { visual - uso } \\
\text { de slide } \\
\text { Apresentaçâo } \\
\text { de aoticias } \\
\text { sobre namoro } \\
\text { en tempos de } \\
\text { pandemia' } \\
\text { violència no } \\
\text { mamoro } \\
\text { 'fenninicidios }\end{array}$ & $\begin{array}{l}\text { Folhetos } \\
\text { informativo } \\
\text { s sobre a } \\
\text { oferta de } \\
\text { liecaciatura } \\
\text { ens } \\
\text { Sociologia e } \\
\text { as } \\
\text { experièncias } \\
\text { pré- } \\
\text { universitziria } \\
\text { s }\end{array}$ \\
\hline
\end{tabular}




\section{Anexo 6 - Descrição dos jogos}

\section{Jogo do Verdadeiro e Falso}

A partir de várias afirmações dentro da temática da igualdade de género, os alunos devem adivinhar a veracidade ou falsidade de cada uma. Este jogo está desenhado numa placa rígida em PVC branco com a impressão das frases e dos espaços para "verdadeiro" e "falso", com velcro, para que possam "colar" uma carinha (feita a partir de tampas de garrafa) naquela que considerem a resposta verdadeira. Na coluna seguinte, também fixada por velcro, encontram as respostas em cartões, que são virados no final do jogo. Para garantir a participação, o jogo é dinamizado pelos próprios alunos. Uma equipa de três voluntários desloca-se para a parte da frente da sala - um segura o quadro, o outro lê as afirmações e reúne a resposta mais votada pela turma (com braços no ar) e um último lê as respostas.

\section{Jogo das Estatísticas}

Inserido na apresentação de slides, a equipa dinamizadora apresenta questões abertas que comparam posições, por exemplo: "Qual a percentagem de homens e de mulheres que compõem a Assembleia da República?". No slide seguinte, e depois das estimativas da turma, aparecem as estatísticas verdadeiras, para que possam ser comentadas.

\section{Jogo das Posições}

Inserido igualmente na apresentação de slides, várias afirmações genéricas vão sendo projetadas, para que os alunos se posicionem em "duas equipas", os que concordam com a afirmação e os que discordam. A partir dessa diferença, abre-se o debate entre os alunos para que cada um explique o seu ponto de vista. 